\title{
The Investigation of Psychological Skills Use between Skilled and Less-skilled Amateur Archers in Hong Kong 香港業餘射箭運動員之技術水平與心理技能使用
}

\author{
Wong Man Sau \\ 黄文秀 \\ Hong Kong Police Archery Club \\ 香港警察箭藝會
}

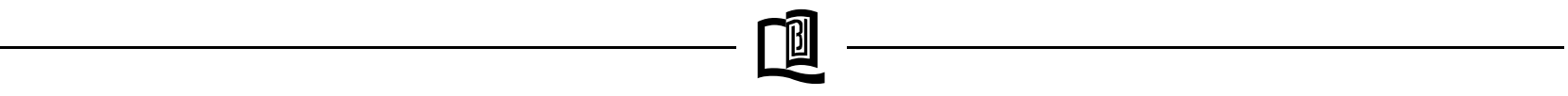

\begin{abstract}
The current study is aimed to investigate the relationship between skilled and less-skilled amateur archers in Hong Kong based on their use of psychological skills. The Test of Performance Strategies (TOPS; Thomas, Murphy, \& Hardy, 1999) was administered to 72 participants (42 skilled and 30 less-skilled; Mean age $=36.07, \mathrm{SD}=12.61$, Range: 18.10 to 63.64 years). The TOPS is a 64-item self-report instrument that can assess a total of 16 psychological skills during practice and competition. Results from t-tests indicated statistically significant differences in the use of psychological skills automaticity during practice and competition between skilled and less-skilled archers. Two binary regression analyses were performed to further investigate the relationship between psychological skills use and skill level. Automaticity in competition and practice subscales were found to have statistically significant predictive powers in accounting for archers' skill level achieved. The regression models indicated a range of $6.1 \%$ to $12.7 \%$ of variance accounted for skill level, and the model successfully classified $58.3 \%$ to $63.9 \%$ of cases per time. These findings link back to a number of skills learning theories that posit it is common to find the automatic stage of skill performance at the highest stage of learning (Haywood,2006).
\end{abstract}

\section{摘 要}

本研究旨在嘹解香港業餘射箭運動員技術水平與心理技能使用的關係。72名射箭運動員分為兩組較高技術水平42人和一般 水平30人，並填寫中文版運動表現策略量表（TOPS）。TOPS可檢测運動竞賽和練習時所用的心理技能。t檢驗結果顯示心理 技能自動化(automaticity)在競賽和練習時的使用在不同技術水平的射手中有顯著差異。本文遂採用囘歸分析以探討心理技能和射 手技術水平的預測和情形。研究結果發現心理技能自動化在競賽和練習的使用可有效預測射箭運動員的技術水平。

\section{Introduction}

Sport psychology is based on the assumption that psychological factors play an important role in determining athletes' performance (Mirzaei, Nikbakhsh, \& Sharififar, 2013). Although psychological skills and physical attributes can both lead to potential athletic success (Humara, 2000), there are psychological differences between successful athletes and less-successful athletes (Gould, Guinan, Greenleaf, Medbery, \& Peterson, 1999). A number of studies have compared the use of psychological skills in athletes who performed highly successfully with their less-successful counterparts. Previous research indicated that successful athletes display some distinctive qualities (Gould et. al., 1999; Ogilvie \& Tutko, 1966; Peetoom, 1987; Stadler, 2007). In the study conducted by Ogilvie and Tutko (1966), successful athletes measured highly on 11 psychological abilities. These are aggression, coachability, conscientiousness, determination, drive, emotional control, guilt proneness, leadership, mental toughness, self-confidence, and trust. To identify the psychological properties that lead to successful athletic performance, Tutko and Ogilvie developed a psychometric test, namely the Athletic Motivation Inventory (AMI). 
From 1975 to 1985, Peetoom (1987) adopted AMI and invited 2101 professional baseball players to participate in the study. The result indicated that self-confidence and determination were the two most consistent traits in predicting elite baseball players. Moreover, emotional control and mental toughness were also found to be of importance. Stadler (2007) compared the AMI scores of college and recreational baseball players. A similar pattern of results emerged: self-confidence, emotional control, and mental toughness (along with drive and aggression) were again the traits that differentiated the low achievers from the high achievers.

Instead of measuring the psychological characteristics only, the athletic coping skills inventory-28 (ACSI-28) was developed to measure the psychological qualities used and strategies employed (Smith, Schutz, Smoll, \& Ptacek, 1995). The ACSI-28 consists of seven scales, each scale consisting of four questions. The scales measurements are similar to the AMI and the strategies are coping with adversity, peaking under pressure, goal setting and mental preparation, concentration, freedom from worry, confidence and achievement motivation, and coachability (Smith et al., 1995). The ACSI-28 was utilized in a wide range of studies. One of the significances is to predict the performance of professional minor league baseball players (Smith \& Christensen, 1995).

The results found that baseball players' psychological and physical skills accounted for nearly equal amounts of explained variance in hitters' batting averages, while psychological skills accounted for most of the explained variance in pitchers' earned run average (ERA) at the end of the season. In addition, confidence and peaking under pressure scales significantly correlated with lower ERA among pitchers. In another study, successful swimmers achieved higher scores on the coping with adversity and peaking under pressure scales (Mummery, Schofield, \& Perry, 2004). Similarly, the coping with adversity scale has shown to be the most accurate predictor that predicts the starting status of American Division I-AA football programs $79.6 \%$ of the time (Spieler et al., 2007). In 2010, Cox, Shannon, McGuire, and McBride investigated the statistically predictive power of psychological skills on athletic performance. Six hundred and ten studentathletes rated their performance subjectively and completed the ACSI-28. The results revealed that after controlling for sex and sport type, psychological skills measured by the ACSI-28 correspond with the performance score that participants have subjectively rated. Among the scales, self-confidence and freedom from worry are psychological skills that are most reliable in predicting performance.

Since committed athletes spend up to $99 \%$ of their time in training rather than in competition (McCann, 1955), an inventory was developed to measure the use of psychological skills in competition and practice. The instrument - Test of Performance Strategies (TOPS) appears to be a more comprehensive tool then AMI and ACSI-28, and can measure up to 16 psychological skills use in practice and in competition (Thomas et al., 1999). The TOPS has been successfully implemented in numerous sports science studies. Furthermore, it has demonstrated a certain degree of relationship between the use of psychological skills and successful performances (Fletcher \& Hanton, 2001; Frey, Lagun, \& Ravizza, 2003; Lowther, Lane, \& Lane, 2002). In the 2000 Sydney Olympic Summer Games study, the TOPS demonstrated significant differences in the use of psychological skills and strategies use between medallists and non-medallists in both competition and practice (Taylor, Gould, \& Rolo, 2008). Inspection using discrimination function analyses found successful US Olympians (defined as medallists) scored lower in imagery, and scored higher in emotional control and automaticity in the competition. During practice, successful US Olympians scored higher in emotional control and positive selftalk. In another study, Thomas et al. (1999) successfully discriminated athletes in different levels (international and non-international levels) by three psychological skills - goal setting, imagery, and activation. Given that the research recruits athletes with different skill levels in different sports, the differences found in the studies were explicable. To justify the relationship between skill level and psychological skills use, perhaps an investigation should be focused on one sport only. In this way, a more comprehensive picture may be provided to this question.

Archery is a shooting sport that is closed skill, discrete, internally paced and requires fine motor skills. This sport demands consistent control and self-regulation associated with a narrow focus of control and a state of flow and unconsciousness during execution (Singer \& Anshel, 2006). Most shooters have an impression that psychological skills play a comparatively larger role in shooting sports than in most other sports (Haywood, 2006). Just like many shooting sports, many athletes 
can shoot well in a short period, but to compete well in competitions, the mental aspect of an athlete always makes a difference (Haywood, 2006; Jarvis, 2006). Therefore, it is important to investigate the relationship between psychological skills use and skill level.

In Hong Kong, archery competitions are regulated by the Hong Kong Archery Association (HKAA). HKAA is a member of the World Archery Federation and the Asian Archery Federation. Based on the level classification of the HKAA, archers are categorised at different levels. The four levels are novice, beginner, intermediate and advance. When an archer obtains a required score in a competition recognised by the HKAA, the archer is promoted to another level. Based on this structure, the study has defined archers who have obtained the advance level skilled, and the rest are defined as less-skilled.

The current research intends to examine the relationship between skill level and the use of psychological skills in archery participation as measured by the TOPS (Thomas et al. ,1999). Two analyses are performed. First, t-tests are used to calculate the differences in psychological skills use between skilled and less-skilled archers. Based on the empirical findings from previous research, skilled athletes obtained better scores on a wide range of scales (e.g. Taylor et al., 2008; Thomas et al., 1999). Therefore, it is hypothesised that skilled archers should obtain better score on a wide range of scales. Second, regression analyses are used to examine whether the use of psychological skills have any contribution towards skill level. The findings of this research would be useful in revising the education in psychological skills use among archers in Hong Kong.

\section{Method}

\section{Subjects}

A total of 72 archers participated in the study 30 of them were defined as less-skilled and 42 were defined as skilled. The ages of the participants ranged from 18.10 to 63.64 years old, with an average age of 36.07 years (standard deviation $=12.61$ ). They were all registered archer of the HKAA.

\section{Materials}

The Test of Performance Strategies is adopted in the study. TOPS is a self-report instrument that was designed to examine the psychological skills and strategies used in both competition and practice (Thomas et al. 1999). The test contains 64 items which assess 16 psychological skills, eight scales measure the use of psychological skills in competition and eight scales measure the use of psychological skills in practice. The eight scales in competition are self-talk, emotional control, automaticity, goal setting, imagery, activation, relaxation, and negative thinking. On the practice, the eight scales are self-talk, emotional control, automaticity, goal setting, imagery, activation, relaxation, and attentional control (descriptions are provided in Appendix 1). The original copy of the TOPS is in English. To accommodate Hong Kong participants' language and conceptual needs, a modified Chinese version of TOPS was developed. The original text was translated and revised based on the study conducted by Hardy, Roberts, Thomas, and Murphy (2010) on the development of TOPS 2 with the purpose of ensuring the power and quality of the instrument.

Participants were asked to respond to the questions based on their subjective feelings to the questions. The questions were on a 5-point Likert-scale. The scales 1 to 5 have verbal anchors of 1 for "Never", 2 for "Rarely", 3 for "Sometimes", 4 for "Often", and 5 for "Always". An example item is "I set realistic but challenging goals for practice." from the English version and “我會訂立實務, 具挑戰性的目標作練習。” from the Chinese version.

Previous studies on the constructs of TOPS have demonstrated good reliability. The different items of the Cronbach's alpha coefficient ranged from .50 to .89 according to previous studies (Hardy et al., 2010; Taylor et al., 2008; Thomas et al. 1999). In terms of validity, the structural integrity is shown to have good statistical support. In the development of TOPS, exploratory factor analysis was used and clear factor structures were shown in both competition and practice items. There were eight factors identified among each competition and practice conditions. In the competition condition, negative thinking replaced attentional control as the eighth factor based on the factor analyses results. According to the latest confirmatory factor analysis (CFA) results conducted by Hardy et al. (2010), data has shown support for all individual subscales in both competition and practice dimensions. 


\section{Data Analysis}

To validate the adapted version of TOPS, the internal reliability of the instrument was examined. The external validity was not inspected due to the limited sample size - subjects-to-variables ratio less than five and without a minimum of 100 observations (Bryant \& Yarnold, 1995). In addition, univariate analyses were performed to examine the data. Previous research has indicated there were gender differences on the psychological skills use (Dachen, 2012). However, the ratio of males to females in the two skill level is similar (skilled archers: 10:20 and less-skilled archers: 15:27). Therefore, no adjustment was made. To examine the difference in the use of psychological skills and skill level, t-tests were conducted. To further examine the extent to which of the eight scales in archery practice or competition is accounted for (can statistically predict) skill level, binary logistic regressions were performed with the psychological skills being the independent variables and the skill level as the dependent variables.

\section{Results}

The reliability of the TOPS scales was tested. The Cronbach's alpha coefficient of the TOPS subscale ranged from .52 to .89 . In the competition dimension, the subscales self-talk, emotional control, automaticity, goal setting, imagery, relaxation, and negative thinking have a Cronbach's alpha coefficient of $.89, .76, .71, .90, .82$, $.84, .79$, and .72 respectively. In the practice dimension, the subscales self-talk, emotional control, automaticity, goal setting, imagery, relaxation and attentional control have a Cronbach's alpha coefficient of $.89, .83, .68, .76$, $.79, .55, .87$, and .65 respectively. The scales practice automaticity (.68) and the practice attentional control (.65) were kept because the Cronbach alpha values were in close proximity to acceptable standards. On the practice activation scale, the coefficient was increased to a level of .77 after question 10, "During practice, I don't think about performing much, I just let it happen." is removed. It is suspected that the Chinese version of question 10 “練習時, 我不會多想自己的表現, 順其自然。” is imprecise for participants to interpret accurately.

Descriptive statistics - range, variance and standard deviation (SD) of the variables are provided in Table 1. In addition, Shapiro-Wilk tests, percent-percent (P-P) plots and quantile-quantile (Q-Q) plots were performed (Field, 2000; Shapiro \& Wilk, 1965). Several scales were observed due to the insignificance value in the normality test. Two TOPS scales from the practice dimension - emotional control and activation were considered to exhibit normal distribution due to the significance being close to .5. In addition, except for the negative thinking scale in the competition dimension being slightly positively skewed, the rest of the scales: emotional control and activation from the competition scales; selftalk and attentional control from the practice scales were slightly negatively skewed.

Impact of skills level. A t-test was conducted to explore the impact of skill level on TOPS, the results are provided in Table 2. On the TOPS competition scales, automaticity was the only scale found to have a statistically significant difference between the skilled and less-skilled archers. The automaticity score was significantly higher among the skilled archers $(\mathrm{M}=$ 3.27, $\mathrm{SD}=.68)$ than the less-skilled archers $(\mathrm{M}=$ 2.91, $\mathrm{SD}=.74), \mathrm{t}(70)=-2.13, \mathrm{P}=.037$, the eta square (.07) indicated there was a moderate effect size. Two psychological skills were found to have marginal differences: $p$ is close to .05. The scales were self-talk and negative thinking. On the self-talk scale, $t(70)=1.94$ $\mathrm{p}=.056$. Skilled archers $(\mathrm{M}=3.27, \mathrm{SD}=.68)$ scored lower than the less-skilled archers $(\mathrm{M}=2.96, \mathrm{SD}=1.03)$, eta square $=.05$. On the negative thinking scale, $\mathrm{t}$ (70) $=1.97, \mathrm{p}=.053$. Participants with higher skill level $(\mathrm{M}=1.98, \mathrm{SD}=.64)$ scored lower than the less-skilled participants $(\mathrm{M}=2.32, \mathrm{SD}=.08)$, eta square $=.05$.

On the practice dimension, a statistically significant difference was found in the automaticity scale, $\mathrm{t}(70)=$ -2.7, $\mathrm{p}=.009$. Again, skilled archers $(\mathrm{M}=3.4, \mathrm{SD}=$ .61) obtained a higher score than the less-skilled archers (M $=2.98, \mathrm{SD}=.7$ ). A moderate effect size was found (eta square $=.09$ ). The results in both archery competition and practice confirmed the hypothesis that skilled archers score higher than less-skilled archers in most of the scales. The only exception was on the negative thinking scale. Negative thinking is an inverted scale, the lower the score obtained, the better an athlete is able to think positively. Therefore, the skilled archers did score better than the less-skilled archers.

Binary regression on skills level and the use of psychological skills. To further examine the relationship in the use of psychological skills by skilled archers and the less-skilled archers, two group of participants were 
compared in two binary regressions analyses. The results identified a certain level of predictive power among two of the psychological skills.

In the competition dimension, a likelihood ratio regression analysis was performed to assess the impact of the use of psychological skills by archers who have attained a higher skill level. A total of eight TOPS scales from competition dimension were inputted. The model was significant $\mathbf{X}^{2}(7, \mathrm{~N}=72)=6.66, \mathrm{p}<$ .05 , indicating that the model is able to distinguish participants who are skilled and less-skilled. The model as a whole explained between $6.1 \%$ (Cox \& Snell R Square) and $8.2 \%$ (Nagelkerke R Square) of the variance in the skills level, and it classified $58.3 \%$ of cases. As shown in table 3 , only one scale made a statistically significant unique contribution to the model. The psychological skill automaticity could serve as a predictor in predicting archer's skill level. The odd ratio for each score in the TOPS psychological skill automaticity was 2.11 more likely to report being in the skilled level.

In the practice dimension, a likelihood ratio regression analysis was performed to assess the impact of the psychological skills use by archers who have attained a higher skill level. A total of eight TOPS scales from the practice dimension were inputted. The model was significant, $\mathbf{X}^{2}(7, \mathrm{~N}=72)=6.66, \mathrm{p}<.05$, indicating that the model is able to distinguish participants who are of a more able or less able level. The model as a whole explained between $9.4 \%$ (Cox \& Snell R Square) and $12.7 \%$ (Nagelkerke $R$ Square) of the variance in the level of skills level, and it classified $63.9 \%$ of cases. As shown in table 4, only one scale made a unique statistically significant contribution to the model. The only predictor is automaticity; the odd ratio for each score in practice automaticity was 2.78 times more likely to report being in the higher skills level.

\section{Discussion}

This paper is intended to explore the relationship between archer's skill level and their use of psychological skills. Results from t-tests demonstrated two statistical significances on the psychological skills use by archers at different skill levels. The hypothesis that skilled archers would obtain better scores on the use of psychological skills was tested. Apart from the significant results from t-tests, skilled archers score better (higher on the positive psychological skills scales; lower on the negative psychological skills scale) on the use of psychological skills than the less-skilled archers in archery participations. The findings from regression analyses outlined two psychological skills use have impact in contributing to better skill level. The psychological skills are automaticity in practice and automaticity in competition. This result brings out the recurring theme in sport psychology that there are psychological differences among skilled athletes and their less-skilled counterparts (e.g. Hardy et al., 1996; Taylor et al. 2008; Thomas et al., 1999). However, the differences found in this study are incomparable with previous findings, further investigation is needed to identify whether the differences are unique to this sport or due to other causes.

In the exploration of psychological skills used by archers at different skills level, automaticity was the only significant variable in predicting skill level. Psychological skill automaticity explained $6.1 \%-8.2 \%$ of the variance in the competition dimension while $9.4 \%-12.7 \%$ in the practice dimension. Of many psychological skills and strategies that were mentioned by Haywood (2006) in "The Sport Psychologist's Handbook", automaticity is the most fundamental skill. In the theory of skills learning, an individual learns by using early cognitive functions such as the conscious control of attention and movements. Through practice, skilled athletes can perform in a relatively automatic state. Similar results were identified in another expert performance study with the use of electromyography (EMG). Hennessy and Parker (1990) examined the electrical activity of two experienced archer's muscles while they were shooting. The research concluded that experienced archers carried out shots at the subconscious level, the automatic stage. Other than examining experienced archers, expert archers also demonstrated similar techniques. Robazza and Bortoli (1998) interviewed eight members of the Italian Olympic archery team to identify psychological factors that were associated with excellence during competition. Archery experts reported the absence of conscious thinking of their movement while executing the shot at a high level of performance, i.e. the movement occurs automatically. The conclusions from the above studies have supported the importance in the use of automaticity.

Automaticity may have provided partial support in obtaining higher skill level. However, this psychological skill only accounted for a small amount of the variance 
in contributing to the skill levels in archery participation. A large amount of variance was left unexplained by this model. Besides, the psychological aspect of archery coaching is not common in Hong Kong. In Hong Kong, archery education is promoted by the HKAA and its affiliated clubs. The basic physical skills and safety guidelines are taught in almost the same way in training courses. However, techniques such as the use of psychological skills and strategies are specific to the knowledge of individual coaches only. Based on the results that skilled archers have a more frequent and higher level use of psychological skills in archery participation, the importance in the use of psychological skills should be emphasized in coach and archer education.

There are three major limitations to the research. First, the sample size is small and insufficient in this study. The reason for this problem is due to the limited population of archers Hong Kong. Therefore, the results of the research may represent archers in Hong Kong only. Second, the reliability of the test requires further examination. In view of the fact that some of the scales in the TOPS inventory display low Cronbach's alpha coefficient, the cause may be due to the use of language, since this is a revised model of TOPS inventory using Chinese as the language medium. The Chinese version of TOPS inventory requires further examination to enhance the internal and external validity. Third, the use of self-reported data in TOPS might not have represented archers' psychological skills use properly. Multiple inventories and resources are suggested in order to obtain a more complete picture of the archers' information.

The results of the current research emphasise the importance in the use of psychological skills. However, athletes should recognize the importance of practice. As mentioned by Haywood (2006), automaticity of the sport movement could be trained: experienced athletes can perform in a relatively automatic stage. In conclusion, the archer-based study provides useful information in evaluating the archery education status of archers in
Hong Kong. Adjustments in the coaching system are suggested to enhance the sport performance. Also, improvement should also be made in the psychological aspect of sports education.

\section{References}

Bryant, F. B., \& Yarnold, P. R. (1995). Principal-components analysis and exploratory and confirmatory factor analysis. In L. G. Grimm \& P. R. Yarnold (Eds.), Reading and understanding multivariate statistics (pp. 99-136). Washington, DC: American Psychological Association.

Cox, R. H., Shannon, J. K., McGuire, R. T., \& McBride, A. (2010). Predicting subjective athletic performance from psychological skills after controlling for sex and sport. Journal of Sport Behavior, 33, 129-145.

Dachen, J. (2012). Test of performance strategies among college going athletes: difference across type of sports and sex. International Journal of Behavioural Social and Movement Science. Retrieved June 29, 2015, from http://www.ijobsms.in/issue4, vol1,p19\%20jigmat. pdf

Fletcher, D., \& Hanton, S. (2001). The relationship between psychological skills usage and competitive anxiety responses. Psychology of Sport and Exercise, 2, 89101.

Frey, M., Laguna, P. L., \& Ravizza, K. (2003). Collegiate athletes' mental skill use and perceptions of success: an exploration of the practice and competition settings. Journal of Applied Sport Psychology, 15, 115-128.

Gould, D., Guinan, D., Greenleaf, C., Medbery, R., \& Peterson, K. (1999). Factors affecting Olympic performance: Perceptions of athletes and coaches from more and less successful teams. The Sport Psychologist, 13, 371-394 
Hardy, L, Roberts, R, Thomas, P, \& Murphy, S. (2010). Test of performance strategies (TOPS): Instrument refinement using confirmatory factor analysis. Psychology of Sport and Exercise, 11, 27-35.

Haywood, K. M. (2006). Psychological aspects of archery. In J. Dosil (Ed.), The sport psychologist's handbook: A guide for sportspecific performance enhancement (Chapter 24). West Sussex, UK: John Wiley \& Sons, Ltd.

Hennessy, M. P., \& Parker, A. W. (1990). Electromyography of arrow release in archery. Electromyography and Clinical Neurophysiology, 30, 7-17.

Humara, M. (2000). Personnel selection in athletic programs. Athletic insight, 2 (2). Retrieved September 29, 2010, from www. athleticinsight.com/Vol2Iss2/Personnel.htm

Jarvis, M. (2006). Sport psychology: A student's handbook. London, Routledge.

Lowther, J., Lane, A., \& Lane, H. (2002). Selfefficacy and psychological skills during the Amputee Soccer World Cup. Athletic Insight, 4(2). http://www.athleticinsight.com/Vol4Iss2/ SoccerSelfEfficacy.htm.

McCann, S. (1995). Overtraining and burnout. In Sport Psychology Inventories. (edited by S. M. Murphy), 347-368. Champaign, IL: Human Kinetics.

Mirzaei, A., Nikbakhsh, R., \& Sharififar, F., (2013). The relationship between personality traits and sport performance. European Journal of Experimental Biology. 3(3), 439-442.

Mummery, K. W., Schofield, G., \& Perry, C. (2004). Bouncing back: The role of coping style, social support and self-concept in resilience of sport performance. Athletic Insight, 6 (3).

Ogilvie, B. C., \& Tutko, T. A. (1966). Problem athletes and how to handle them. London: Palham.
Peetoom, G. A. (1987). Predicting success in professional baseball with the Athletic Motivation Inventory. Unpublished Doctoral Dissertation, University of Mississippi.

Robazza, C., \& Bortoli, L. (2006). Mental preparation strategies of Olympic archers during competition: an exploratory investigation. High Ability Studies, 9 (2), 219-235, DOI: $1.1080 / 1359813980090207$

Singer, R. N. \& Anshel, M. H. (2006). An overview of interventions in sport. In J. Dosil (Ed)., The sport psychologist's handbook: A guide for sport-specific performance enhancement (pp. 63-88). New York: Wiley.

Smith, R. E. \& Christensen, D. S. (1995). Psychological skills as predictors of performance and survival in professional baseball. Journal of Sport and Exercise Psychology, 17, 399- 415.

Smith, R. E, Schutt, R. W., Smoll, F. L, \& Pacek, J. T. (1995). Development and validation of a multi-dimensional measure of sport-specific psychological skills: The athletic coping skills inventory-28. Journal of Sport \& Exercise Psychology, 17, 379-398.

Spieler, M., Czech, D. R., Joyner, A. B., Munkasy, B., Gentner, N., \& Long, J., (2007). Predicting athletic success: factors contributing to the success of NCAA division I AA collegiate football players. Athletic Insight, 9 (2).

Stadler, M (2007). The Psychology of Baseball: Inside the Mental Game of the Major League Player. New York: Gotham.

Taylor, M. K., Gould, D., \& Rolo, C. (2008). Performance strategies of U.S. Olympians in practice and competition. High Ability Studies, 19, 19-36.

Thomas, P. R., Murphy, S. M., \& Hardy, L. (1999). Test of performance strategies: development and preliminary validation of a comprehensive measure of athletes' psychological skills. Journal of Sports Sciences, 17(9), 697-711. 
Table 1. Descriptive Statistics on TOPS Scales.

\begin{tabular}{|c|c|c|c|c|c|c|c|c|c|c|}
\hline \multirow{2}{*}{ Subscale } & \multirow{2}{*}{$\begin{array}{c}\text { Cronbach's } \\
\text { alpha }\end{array}$} & \multicolumn{4}{|c|}{ Distribution } & \multicolumn{4}{|c|}{ Dispersion } & \multirow{2}{*}{$\begin{array}{c}\begin{array}{c}\text { Shape of } \\
\text { distribution }\end{array} \\
\text { Shapiro-Wilk Tes }\end{array}$} \\
\hline & & Mean & Median & Mode & Range & Variance & SD & Skewness & Kurtosis & \\
\hline \multicolumn{11}{|l|}{ Competition } \\
\hline ST & .89 & 3.21 & 3.25 & 4.00 & 4.00 & .89 & .94 & -.38 & -.40 & .12 \\
\hline $\mathrm{EC}$ & .76 & 3.47 & 3.50 & 3.50 & 4.00 & .57 & .76 & -.79 & .79 & .01 \\
\hline Aut & .71 & 3.12 & 3.25 & 3.25 & 4.00 & .52 & .72 & -.37 & 1.00 & .11 \\
\hline GS & .90 & 3.43 & 3.50 & 3.00 & 4.00 & .99 & .99 & -.28 & -.43 & .08 \\
\hline I & .82 & 2.95 & 3.00 & 2.50 & 4.00 & .79 & 89 & -.05 & -.36 & .31 \\
\hline Act & .84 & 3.69 & 4.00 & 4.00 & 3.25 & .54 & .73 & -.67 & -.03 & .00 \\
\hline $\mathrm{R}$ & .79 & 3.25 & 3.25 & 3.00 & 3.25 & .54 & .73 & -.17 & .16 & .17 \\
\hline NT & .72 & 2.12 & 2.00 & 1.75 & 3.75 & .53 & .72 & 1.09 & 1.84 & .00 \\
\hline \multicolumn{11}{|l|}{ Practice } \\
\hline ST & .89 & 3.16 & 3.25 & 4.00 & 4.00 & 1.04 & 1.02 & -.47 & -.72 & .00 \\
\hline $\mathrm{EC}$ & .83 & 3.50 & 3.50 & 3.75 & 3.25 & 69 & 83 & -.19 & -.64 & .05 \\
\hline Aut & .68 & 3.23 & 3.25 & 3.00 & 3.75 & .46 & 68 & -.30 & .66 & .11 \\
\hline GS & .76 & 3.30 & 3.38 & 3.75 & 3.75 & .73 & 85 & -.26 & -.32 & .27 \\
\hline I & .79 & 2.91 & 2.88 & 2.75 & 3.75 & .77 & 88 & .08 & -.27 & .42 \\
\hline Act & .77 & 3.35 & 3.50 & 3.75 & 3.25 & .44 & .66 & -.39 & -.03 & .05 \\
\hline $\mathrm{R}$ & .87 & 3.12 & 3.25 & 3.25 & 4.00 & .90 & .95 & -.10 & -.35 & .27 \\
\hline $\mathrm{AC}$ & .65 & 3.36 & 3.50 & 3.75 & 3.25 & 46 & 68 & -.34 & .28 & .04 \\
\hline
\end{tabular}

Note. ST = Self-talk, EC = Emotional control, Aut = Automaticity, GS = Goal Setting, $\mathrm{I}=$ Imagery, Act = Activation, $\mathrm{R}$ $=$ Relaxation, $\mathrm{NT}=$ Negative thinking, $\mathrm{AC}=$ Attentional Control.

Table 2. Means (M), Standard Deviation (SD), and t Values for Participants with different Skills Level among NEO-FFI and TOPS scales.

\begin{tabular}{|c|c|c|c|c|c|c|c|}
\hline \multirow[b]{2}{*}{ Subscales } & \multirow[b]{2}{*}{ M } & \multicolumn{2}{|c|}{ Less-skilled ( $\mathrm{n}=30$ ) } & \multicolumn{2}{|c|}{ Skilled $(\mathrm{n}=42)$} & \multirow[b]{2}{*}{$\mathrm{p}$} & \multirow[b]{2}{*}{ Eta square } \\
\hline & & $\mathrm{SD}$ & M & $\mathrm{SD}$ & $\mathrm{t}$ & & \\
\hline \multicolumn{8}{|c|}{ Competition } \\
\hline ST & 2.96 & 1.03 & 3.39 & 84 & -1.94 & .06 & .05 \\
\hline $\mathrm{EC}$ & 3.38 & .71 & 3.52 & .79 & -.78 & 44 & .01 \\
\hline Aut & 2.91 & .74 & 3.27 & .68 & -2.13 & .04 & .06 \\
\hline GS & 3.28 & 1.09 & 3.54 & .92 & -1.07 & .29 & .02 \\
\hline I & 2.86 & .93 & 3.01 & 86 & -.72 & 47 & .01 \\
\hline Act & 3.60 & .89 & 3.75 & 60 & -.85 & .40 & .01 \\
\hline $\mathrm{R}$ & 3.09 & .77 & 3.36 & .70 & -1.53 & .14 & .03 \\
\hline NT & 2.32 & .80 & 1.98 & .64 & 1.97 & .05 & .05 \\
\hline \multicolumn{8}{|l|}{ Practice } \\
\hline ST & 2.93 & 1.08 & 3.33 & .95 & -1.70 & .09 & .04 \\
\hline $\mathrm{EC}$ & 3.41 & .90 & 3.56 & .79 & -.76 & .45 & .01 \\
\hline Aut & 2.98 & .70 & 3.40 & 61 & -2.70 & .01 & .09 \\
\hline GS & 3.21 & .92 & 3.36 & 80 & -.73 & 47 & .01 \\
\hline I & 2.81 & .83 & 2.99 & 91 & -.86 & 40 & .01 \\
\hline Act & 3.27 & .66 & 3.42 & 67 & -.94 & .35 & .01 \\
\hline $\mathrm{R}$ & 2.93 & .92 & 3.26 & .95 & -1.47 & .15 & .03 \\
\hline $\mathrm{AC}$ & 3.26 & .66 & 3.43 & .69 & -1.09 & .28 & .02 \\
\hline
\end{tabular}

Note. Self-talk $=$ ST, Emotional control $=\mathrm{EC}$, Automaticity $=$ Aut, Goal setting $=\mathrm{GS}$, Imagery $=\mathrm{I}$, Activation $=$ Act, Relaxation $=\mathrm{R}$, Negative thinking $=\mathrm{NT}$, Attentional control $=\mathrm{AC}$. 
Table 3. Logistic Regression in Predicting the Psychological Skills Use in the Competition Dimension that have Contributed to the Skills Level.

\begin{tabular}{llllllllll}
\hline & & & & & & & \multicolumn{3}{c}{$95 \%$ C. I. } \\
\cline { 6 - 9 } Scale & B & S. E. & Wald & d.f. & p & Odds Ratio & Lower & Upper \\
\hline A utomaticity & .745 & .370 & 4.058 & 1 & .044 & 2.11 & 1.020 & 4.350 \\
\hline
\end{tabular}

Table 4. Logistic Regression in Predicting the Psychological Skills Use in Practice Dimension that have Contributed to the Skills Level.

\begin{tabular}{llllllllll}
\hline Scale & B & S. E. & Wald & d.f. & $p$ & Odds Ratio & Lower & Upper \\
\hline A utomaticity & 1.02 & .41 & 6.10 & 1 & .01 & 2.78 & 1.24 & 6.24 \\
\hline
\end{tabular}

Appendix 1. A List of Descriptions on the Test of Performance Strategies on the Psychological Skills Use

\begin{tabular}{|c|c|c|}
\hline Scales & $\begin{array}{l}\text { Competition / Practice } \\
\text { Dimension }\end{array}$ & Descriptions by Dachen 2012 \\
\hline Self-talk & Both scales & M aintaining a positive internal dialogue \\
\hline Emotional Control & Both scales & Controlling emotion under pressures \\
\hline A utomaticity & Both scales & $\begin{array}{l}\text { Performing with little conscious effort and the } \\
\text { movement is able to carry out automatically }\end{array}$ \\
\hline Goal Setting & Both scales & Setting personal and specific goals for the game \\
\hline Imagery & Both scales & Visualization sport performance \\
\hline Activation & Both scales & M aintaining an optimal level of arousal \\
\hline Relaxation & Both scales & Practicing to remain calm under pressures \\
\hline Negative thinking & Competition scale & Thoughts of failure \\
\hline Attentional Control & Practice scale & Focusing attention effectively \\
\hline
\end{tabular}

\section{Correspondence}

Author: Wong Man Sau

作者: 黃文秀

Affiliation: Hong Kong Police Archery Club

所屬機構: 香港警察箭藝會

Postal address: A2, 2/F, Greenwood Villas 1,

2-3 Chung Shan Terrace, Lai Chi Kok, Kln, HK

Telephone number: +8529543 5582

Email address: wong0723@connect.hku.hk

\section{Acknowledgement}

The data of this research was extracted from the thesis "Personality Traits, Psychological Skills, and Skills Level among Amateur Archers in Hong Kong", a thesis submitted to fulfill the requirements for the degree of Master of Education at The University of Hong Kong in August 2015. 